\title{
Stratification at the Health District Level for Targeting Malaria Control Interventions in Mali
}

\section{Mady Cissoko}

Aix marseille Univ, INSERM, IRD, SESSTIM, ISSPAM, UMR 1225, 13005 Marseille

https://orcid.org/0000-0002-0200-8191

\section{Mahamadou Magassa}

Conseil National de Lutte contre le Paludisme

Vincent Sanogo

Conseil National de Lutte contre le Paludisme

\section{Abdoulaye Ouologuem}

Institut National de Sante Publique

\section{Lansana Sangaré}

Laboratoire de Biologie Moléculaire Appliquée

Modibo Diarra

Malaria Research and Training Center

\section{Cedric Stephane Bationo}

Aix marseille Univ, INSERM, IRD, SESSTIM, ISSPAM, UMR 1225, 13005 Marseille

\section{Amagoron dit Mathias Dolo}

Malaria Research and Training Center

\section{Mamadou D. Bah}

president's Malaira Initiative (PMI) VectorLink Projet

\section{Sidy Doumbia}

Malaria Research and Training Center

\section{Mamadou B. Coulibaly}

MRTC: Malaria Research and Training Center

\section{Diahara Traoré}

Programme National de Lutte contre le Paludisme

\section{Boubacar Sidibé}

Organisation mondiale de la Santé pour Afrique: Organisation mondiale de la Sante pour Afrique Jordi Landier

Aix marseille Univ, INSERM, IRD, SESSTIM, ISSPAM, UMR 1225, 13005 Marseille Idrissa Cissé

Programme National de Lutte contre le Paludisme

\section{Moussa Sacko}

Institut National de Sante Publique 


\section{Jean Gaudart ( $\nabla$ jean.gaudart@univ-amu.fr)}

9 Aix Marseille Univ, APHM, INSERM, IRD, SESSTIM, ISSPAM, UMR1252, Hop Timone, BioSTIC, Biostatistic \& ICT, 13005 Marseille, France https://orcid.org/0000-0001-9006-5729

\section{Issaka Sagara}

Malaria Research and Training Center

\section{Research}

Keywords: Stratification, Malaria, Interventions, geo-epidemiology, environment, Mali

Posted Date: July 16th, 2021

DOI: https://doi.org/10.21203/rs.3.rs-653056/v2

License: (c) (i) This work is licensed under a Creative Commons Attribution 4.0 International License.

Read Full License 
1 Stratification at the Health District Level for Targeting Malaria Control Interventions in 2 Mali

3 Mady Cissoko ${ }^{1,2,3}$, Mahamadou Magassa ${ }^{4}$, Vincent Sanogo ${ }^{4}$, Abdoulaye Ouologuem ${ }^{5}$, Lansana Sangaré ${ }^{6}$, Modibo Diarra ${ }^{1}$,

4 Cedric Stephane Bationo ${ }^{3}$, Amagoron dit Mathias Dolo ${ }^{1}$, Mamadou D. Bah ${ }^{7}$, Sidy Doumbia ${ }^{1}$, Mamadou B. Coulibaly ${ }^{1}$, Diahara

Traoré $^{4}$, Boubacar Sidibé ${ }^{8}$, Jordi landier ${ }^{3}$, Idrissa Cissé ${ }^{4}$, Moussa Sacko ${ }^{5}$, Jean Gaudart ${ }^{9 *}$, Issaka Sagara ${ }^{1,3}$.

Affiliations :

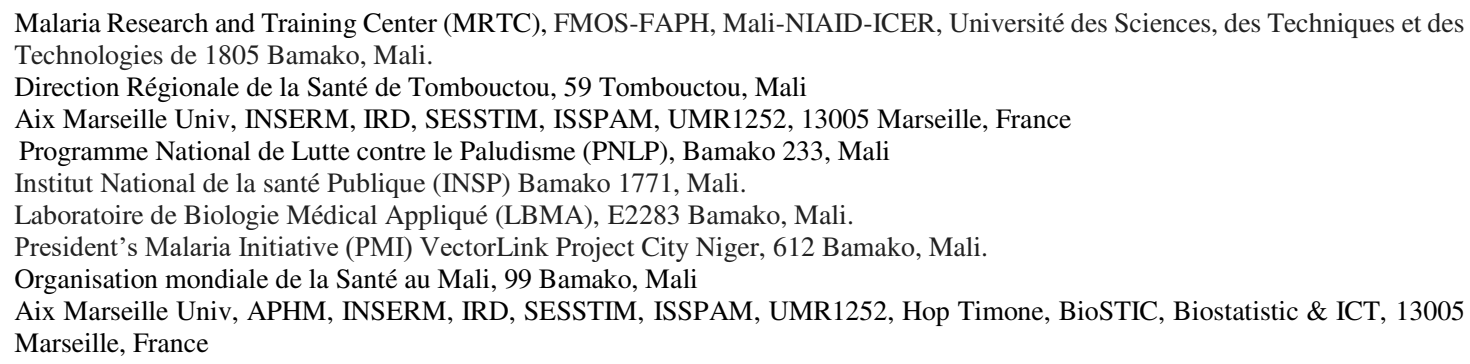

* Corresponding author: Jean Gaudart, Email: jean.gaudart@univ-amu.fr

Abstract

\section{Introduction}

Malaria has been the main cause of morbidity and mortality in Mali, with an increase from 2017 to 2020 (2,884,837 confirmed cases and 1,454 deaths). On the recommendation of the World Health Organization (WHO) and for efficient use of resources, Mali has begun a process of malaria stratification.

\section{Method}

Malaria, entomological and environmental data were collected through the local health information system, the Demographic and Health Survey 2018, research institutions and MALI-METEO services. The WHO stratification based on malaria incidence was used to present a stratified malaria risk map. Environmental factors associated with malaria were identified using a general additive non-linear regression model. The classification and regression tree method was used to improve the stratification. Interventions were proposed according to the incidence stratification and the different environmental, entomological, access to care maps.

\section{Results}

From 2017 to 2019, the median incidence across the 75 health districts was 129.34 cases per 1,000 person-year (IQR=86.48). Stratification resulted in 12 health districts of very low, 19 low, 20 moderates and 24 in high transmission areas. Considering the environmental risk associated to malaria incidence, 6 environmental classes were selected. Four different strategies were proposed, from improving 
surveillance and response to epidemic in the very low and low zones, to access to care improvement in the moderate and high zone.

\section{Conclusion}

This stratification in Mali will allow targeting malaria control strategies.

Keywords: Stratification, Malaria, Interventions, geo-epidemiology, environment, Mali.

\section{Background}

Malaria remains the leading cause of morbidity and mortality in Mali. In 2020, the surveillance system reported 2,884,827 confirmed cases out of 4,252,213 people tested, of which 871,265 were severe cases, still being the first reason for health care visits with $36 \%$ of consultation due to malaria ${ }^{1}$. The number of deaths was 1,454 notified by the health facilities. The main parasites responsible for malaria in Mali are: Plasmodium falciparum (more than 85\%), Plasmodium malariae (10-15\%) and Plasmodium ovale $(1 \%)^{2}$. However, cases of Plasmodium vivax have been observed and documented in Mali ${ }^{3,4}$. Malaria is endemic in most localities in Mali with an annual increase following the rainy season. The main vector species are: Anopheles gambiae s.l. (Anopheles gambiae s.s., Anopheles coluzzii, Anopheles gambiae and Anopheles arabiensis) and Anopheles funestus 5,6.

To control malaria, Mali has implemented a policy of prevention, monitoring and case management coordinated at different levels by the National Malaria Control Program (NMCP) following the World Health Organization (WHO) technical guidelines. The case management is concerned with the early diagnosis of malaria by rapid diagnosis test (RDT) and prompt treatment. Preventive interventions are vector control using insecticide-treated mosquito nets (ITNs) distributed every 3 years, and indoor residual spraying (IRS). Seasonal Malaria Chemoprevention (SMC) has been progressively applied since 2012, for children under 5 years old during the periods of high transmission (one per month from July to October) using the Sulfadoxine-pyrimethamine (SP) associated to Amodiaquine (AQ). Intermittent Preventive Treatment (IPT) with Sulfadoxine-pyrimethamine (SP) has been applied since 2000 for pregnant women from the $13^{\text {th }}$ week of pregnancy.

WHO recommends that malaria-endemic countries adapt interventions as transmission evolves ${ }^{7}$. The intensity of malaria transmission is strongly dependent on environmental, socio-demographic characteristics and the malaria interventions implemented ${ }^{8-12}$. It is generally measured by the incidence of cases or the prevalence of infection in the population.

Malaria stratification is defined as the classification of geographical areas according to similar epidemiological, entomological, environmental and socio-economic factors, in order to guide malaria control interventions ${ }^{7}$. Health districts are classified according to the risk, based on factors that 
determine susceptibility and vulnerability to malaria transmission. These stratum or facies are places in which malaria presents the same characteristics of transmission and incidences. Stratifying malaria allows better targeting of malaria control strategies in Mali.

In 1989, Mali has been divided into 5 zones corresponding to the initial epidemiological facies described: i) a Sudano-Guinean zone with a long seasonal transmission of 4 to 6 months; ii) a zone of short seasonal transmission of 3 to 4 months; iii) a zone of sporadic or epidemic transmission in the northern regions and some localities in the regions of Koulikoro, Segou, Mopti and Kayes; iv) zones of bi or multimodal transmission including the inner delta of the Niger River and dam zones; v) zones that are less propitious to malaria transmission, particularly in urban areas as Bamako and Mopti where malaria was hypo endemic ${ }^{13}$. Since 1989 , these profiles have evolved, due to sociological and climatic changes.

The aim of this study was to develop an updated stratification of malaria in Mali in order to target interventions based on the intensity of transmission, environmental risk, vector resistance and distribution.

\section{Method}

\section{Study location}

The Republic of Mali, a country located in West Africa and in the Sahelo-Saharan strip, has a population of 20,536,999 inhabitants in 2020 and a growth rate of 3.36\% (General Population, Habitat Survey 2009 in Mali -GPHS 2009-, updated by the National Population Direction). The relief is low, with an average altitude of 500 meters, showing landscapes of plains and low plateaus. The hydrographic regime, associated with the geographical profile from the $11^{\circ}$ and the $25^{\circ}$ north latitude, is constituted by the 2 basins of upper Senegal and Niger Rivers. There are several dams and flooded areas used for agriculture. The flooded areas extend along the Niger River: the inner delta of the Niger River from the Segou region in the center, through Mopti to the Timbuktu region in the north (Figure 1), and covers a maximum area of $41,000 \mathrm{~km}^{2}$, including numerous lakes, ponds and swamps ${ }^{14}$. Annual rainfall data measured vary from less than $200 \mathrm{~mm}$ in the Saharan desertic zone to more than $1100 \mathrm{~mm}$ in the pre-Guinean zone (Figure 1): desertic zone (less than $200 \mathrm{~mm}$ ), Sahelian zone (200 to $600 \mathrm{~mm}$ ), Sudanian zone (600 to $800 \mathrm{~mm}$ ), Sudano-Guinean zone (800 to $1100 \mathrm{~mm}$ ) and the pre-Guinean zone (more than $1100 \mathrm{~mm})^{15}$.

Figure 1: Different ecoclimatic zones in Mali (Source: MRTC GIS/RS). 
Mali is composed of 11 regions including the District of Bamako. The health system is divided into 75 health districts. The health system is structured following a 3-level pyramid (health district, regional and national level).

\section{Data collection}

Clinical data

Malaria cases confirmed by a biological test (RDT or microscopy), notified monthly by the health districts, were extracted from 2017 to 2019. The attendance rate was also collected into the District Health Information Software 2 (DHIS2) platform by health districts. The child mortality data were extracted from the Demographic and Health Survey (DHS).

The use of anonymous data was obtained from the National Malaria Control Program (NMCP) (DHIS2 data extractions), or from research institutions: Malaria Research and Training Center (MRTC), Laboratory of Applied Molecular Biology (LBMA) and National Institute of Public Health (INSP).

113 Updated population data were obtained from the GPHS 2009 updated by the National Population Direction, at the health district and regional levels.

\section{Environmental data}

116 Environmental data were collected from the MALI-METEO service (observational data from synoptic and agrometeorological stations for the Center and South regions) and from the NASA - GIOVANNI platform (giovanni.gsfc.nasa.gov/). The data collected were: the monthly rainfall in mm (IMERG 6, resolution $1^{\circ}$ ), the monthly NDVI (MODIS-terra, resolution 0.05 ), the monthly maximum and minimum temperature in Celsius degrees (AIRS, resolution $1^{\circ}$ ), the monthly relative humidity (AIRS, resolution $1^{\circ}$ ), the monthly soil moisture in $\mathrm{m} 3 \mathrm{~m}-3$ (MERRA-2, resolution $0.5 \times 0.625^{\circ}$ ) and the monthly mean wind speed in $\mathrm{m} / \mathrm{s}\left(\text { MERRA-2, resolution } 0.5 \times 0.625^{\circ}\right)^{16}$. The land use data, i.e. percentage of cultivated area, percentage of urbanization, percentage of area occupied by trees and surface water, were obtained from the 2017 Copernicus Africa classification ${ }^{17}$.

Entomological data

The entomological data presented here includes data from 2010 to 2019, from Malaria Research and Training Center (MRTC) and the NMCP partner (Vector Link) carried to the national sentinel sites 5,6,18,19. Two parameters were studied: vector distribution and vector resistance to insecticides to ten insecticides in five classes (pyrethroids -PY-, organochlorines -OC-, organophosphates -OP-, 130 carbamates and neonicotinoids). The insecticides used were permethrin $0.75 \%$, deltamethrin $0.05 \%$, alpha-cypermethrin $0.05 \%$ and lambda-cyhalothrin $0.05 \%$ (pyrethroids), DDT $4 \%$ (organochlorinated), bendiocarb $0.1 \%$ and propoxur 0.1 (carbamates); pyrimiphos-methyl $0.25 \%$ and $1 \%$ and fenitrothion 
$1 \%$ (organophosphates) and clothianidin $2 \%$ (neonicotinoid). The tests performed were bioassays according to WHO recommendations [12] on the major malaria vector An. gambiae s.l.

\section{Data Analysis}

Incidence and prevalence data were estimated and presented in maps, tables, and figures.

To determine the periods of transmission at the national level, the national malaria incidence time series was split using the change point analysis of the mean. The algorithm PELT was used ${ }^{20}$, allowing the identification of periods of low and high transmission.

As the impacts of environmental determinants of malaria are well documented in Mali 9,21,22, relationships between environmental factors and malaria incidence was assessed including time lags. For this purpose, we provided synthetic environmental indices (SEI) by using principal component analysis (PCA). This approach was necessary to consider the curse of dimensionality and collinearities between variables. The number SEI was chosen according to the elbow criterion ${ }^{23}$.

The relationships between synthetic environmental indices and malaria incidences were assessed by using Generalized Additive Model (GAM), using Spline smoothing functions modeling non-linear relationships, Negative-binomial distribution for count data considering overdispersion, and log (Population) as offset to provide standardized incidence ratios (SIR). The time series of monthly incidences was modeled as a function of environmental factors grouped into synthetic environmental indices by the PCA method with a lag of 1 to 4 months. The criterion for selecting the best model was the highest explained deviance and the lowest model generalized cross-validation score (GCV).

Spatial analysis

Monthly incidences were estimated using confirmed malaria cases reported by DHIS2 considering the population size and time (month).

$$
\text { incidence }=\frac{\text { cases }}{\text { population } \times \text { time }} \times 1,000(2)
$$

157 These crude estimations did not totally reflect the real incidence of the disease in the population for the following reasons varying according to the health facilities:

- Health facility access and usage rate

- The availability and use of diagnostic tests

- The low completeness of the databases by health facilities.

Adjusted incidences were estimated per 1,000 person-years by adjusting for the health district usage rate as follow: 
167 To stratify malaria, we first used the WHO criteria to classify the health districts. This stratification was

168 improved in a second step by using meteorological and land use factors. These classes were determined by Classification and Regression Trees (CART) ${ }^{24}$.

\section{Software and packages}

171 The R software version 3.4 was used for the statistical analyses ( $\mathrm{R}$ Development Core Team, $\mathrm{R}$

172 Foundation for Statistical Computing, Vienna, Austria), using the following packages:

$173\{$ mgcv $\}\{$ caschrono $\}\{$ FactoMineR $\}\{$ forecast $\}\{$ ggplot 2$\}\{$ party $\}\{$ changepoint $\}$. The ArcGIS Desktop 174 version 10.1 software (Environmental Systems Research Institute (ESRI), 380 New York Street, 175 Redlands, CA 92373-8100, USA) was used for mapping. The Paint.net software version 4.2.13 (Rick

176 Brewster and al., Washington State University, USA) was used for image treatment.

\section{Results}

\section{Temporal}

179 Low and high malaria transmission period

180 Time series analysis of the monthly malaria incidence showed the classical periodicity at the national scale, with a lag according to the rainfall.

Figure 2: Malaria incidence time series, 2017-2019. Grey band: periods of high malaria transmission (according to the change point analysis); Blue bars: rainfall (left y-axis, mm); Red curve: Malaria incidence (y-right axis, cases/person-month); Black curve: average monthly temperature in a black (yright axis, $\left.{ }^{\circ} \mathrm{C}\right)$.

\section{Relationship between malaria and environmental factors}

Principal component analysis of environmental factors 
192 Figure 3: synthetic indices from the Principal Component Analysis (PCA) of the different meteorological factors.

194 PCA allowed to obtain two Synthetic Environmental Indices (SEI) with 87.7\% inertia (Figure 3 Panel 195 a). SEI 1 was determined by rainfall, relative humidity, soil moisture and NDVI positively and wind speed negatively. SEI 2 was mainly determined by temperatures (Figure 3, Panel b).

Uni and multivariate regression analysis

The univariate regression analysis by using general additive modeling (GAM) showed a month lag between SEI 1 (rainfall, relative humidity, vegetation index and soil moisture) and malaria and no lag between SEI 2 (temperature) and malaria incidence.

Considering these lags, the multivariate analysis showed a linear relationship between malaria incidence and the SEI 1 (rainfall, NDVI, relative humidity and soil moisture) (p-value $<0.001$ ), before reaching an asymptote for high values (Figure 4, panel a). Malaria incidence decreased with high values of SEI 2 (temperatures) (p-value < 0.01) (Figure 4, panel b).

Figure 4: Changes in malaria incidence as a function of synthetic environmental indices; GAM multivariate analysis.

Spatial analysis

Adjusted Malaria incidence

212 Annual adjusted malaria incidence at the health district level for 2019 was stratified into five (5) classes

213 per 1,000 person-years. The median incidence was 125.34 cases per 1,000 person-year with a standard 214 deviation of 86.48.

Figure 5: Annual malaria incidence at the health district level, adjusted for health facility access, Mali, 2172019.

218 According to the WHO classification, the adjusted malaria incidence in 2019, Mali, was distributed as 219 follow (Figure 5 and Figure 13 panel B): 
- 12 out of 75 health districts in the zone of very low transmission with 100 cases per 1,000 person-years: 7 health districts showing incidences between 5 to 50 cases per 1,000 personyears (located in the northern area) and 5 health districts showing incidences between 50 and 100 cases per 1,000 person-years ( 3 in the northern area, one in the western area, one in Bamako);

- 19 out of 75 health districts in the low transmission zone;

- 20 out of 75 health districts in the moderate transmission zone;

- 24 out of 75 health districts in the high transmission zone (mainly in the southern and centralwestern areas).

Rainfall

Figure 6: Map of average annual rainfall from 2017 to 2019 by health district in Mali.

The average annual rainfall from 2017 to 2019 varies from less than $200 \mathrm{~mm}$ in the desertic zone to more than $1100 \mathrm{~mm}$ in the Sudano-Guinean zone, with a clear north to south trend. Within the 75 health districts, 17 showed an average rainfall of less than $200 \mathrm{~mm}$ (desertic zone), 20 showed an average rainfall between 200 and $600 \mathrm{~mm}$ (Sahelian zone), 10 showed an average rainfall between 600 and 800 $\mathrm{mm}, 21$ showed an average rainfall between 800 and $1100 \mathrm{~mm}$ (Sudanese) and 7 health districts showed an average rainfall above $1100 \mathrm{~mm}$ (Sudano-Guinean zone).

\section{Health facility access}

The percentages of populations living outside a distance of 5-km from a health facility was high in Mali, mainly in the northern areas, justifying the implementation of specific strategies to improve care access.

Figure 7: Percentage of population outside at 5-km radius of a health facility in Mali 2019

\section{Prevalence of malaria in children aged 3-59 months}

Figure 8: Malaria prevalence map of children aged 6-59 months according to DHS VI, Mali 2018.

Malaria prevalence according to DHS VI 2018 was $18.9 \%$ at the national level among children aged 659 months in Mali. The prevalences were lower in the northern regions of Kidal, Taoudenit, Tombouctou 
between 1 and 10\% and the District of Bamako less than 1\%. Two regions in the North such as Gao and Ménaka showed a prevalence over $10 \%$. The regions of Sikasso, Ségou and Mopti showed the highest prevalence with $29.7 \%, 25.9 \%$ and $24.9 \%$ respectively.

Child mortality in Mali

Figure 9: Map of mortality of children under 5 years old from DHS 2018 survey in Mali.

256

The regions of Kidal and Gao and the District of Bamako showed the lowest mortality rates of 20, 78 and 55 per 1000 cases respectively.

\section{Entomological maps}

Figure 10: Malaria vector distribution map, 2010 - 2019. The sector diagrams show the presence of the different species.

The malaria vectors found at the sentinel and research sites were distributed ubiquitously. These are $A n$. coluzzii, An. gambiae and An. arabiensis (to a lesser degree compared to the first two). In the northern regions, Gao, Kidal and Timbuktu, the studies carried out were morphological identification, identifying only An. gambiae s.l.. The An. funestus group was also encountered particularly in the area of Niono and Mopti (inner delta).

Figure 11: Map distribution of resistance of Anopheles gambiae s.l., a major malaria vector to different insecticides from 2010 to 2019 in Mali. Red dots show the presence of insecticide resistance in the health district, yellow dots show moderate sensitivity (below 90\%) and green dots show a high sensitivity of major vectors to insecticide.

High resistance to pyrethroids and organochlorines was observed in several health districts. Resistance to carbamates (bendiocarb and propoxur) was also noted, although it appears to be less extensive than resistance to pyrethroids. The bioassays showed that the major malaria vector was sensitive to pyrimiphos-methyl (OP) and clothianidin (neoticotinoid). Sensitivity and resistance to fenitrothion (OP) were noted in sentinel sites where entomological surveillance was carried out. Deltamethrine LLIN is currently mainly distributed, whatever the resistance analyses. Pyrethroid-PBO combination-LLIN are proposed for 2023 distributions. 
The supervised classification (CART) provided 6 classes of malaria incidence based on environmental factors (Figure 12). Vegetation (NDVI) was the first factor that split first the northern and the southern part. Then, within the northern part, the classification identified a low vegetation area around the Niger River (a West to East area from Niafunke to Inekar, class 3), showing an intermediate adjusted incidence around 100 cases per 1000 person-year. The extreme north area (classes 1 and 2), with a very low vegetation index (sahara area), were split according to the surface water factor (no surface water vs oases or wadis), experienced adjusted incidences around 50 and 100 cases per 1000 person-year, respectively.

Within the southern part, with higher vegetation index, temperatures were the main factors to classify the areas. Indeed, high nighttime temperature $\left(>22^{\circ} \mathrm{C}\right)$ in the urbanized areas of Bamako and Kayes (class 6) was associated with intermediate malaria adjusted incidence, around 150 cases per 1000 person-year. Then, near the Kayes area, the fifth class was associated with high daily temperature (above $37.48{ }^{\circ} \mathrm{C}$ ), experiencing incidences around 250 cases per 1000 person-year. Finally, the major class (class 4), with 41 health districts among 75, with high vegetation index and low night and day temperature, experienced malaria adjusted incidences around 500 cases per 1000 person-year. This area included the Niger River inner delta in central Mali, the Senegal River basin area (Senegal River and its tributaries, south-west) and the Sudan-Guinean area (south).

Figure 12: Environmental supervised classification of malaria in Mali (CART). Class 1: Very low vegetation and no surface water; Class 2: Very low vegetation around oases or wadis; Class 3: Low vegetation around the northern part of the Niger River; Class 4: higher vegetation index, low night and day temperatures $\left(<22^{\circ} \mathrm{C},<37.47^{\circ} \mathrm{C}\right.$, respectively); Class 5: higher vegetation index, high daily temperature $\left(>37.47^{\circ} \mathrm{C}\right)$ and low night temperature $\left(<22^{\circ} \mathrm{C}\right)$; Class 6: higher vegetation index, high night temperature $\left(>22^{\circ} \mathrm{C}\right)$. NDVI: Normalized Difference Vegetation Index; TN: Night Temperature; TD: Daily Temperature; WS: Water Surface

Figure 13: Malaria transmission zones in Mali according to adjusted incidence. Panel A: eligible interventions according to strata and information on insecticide resistance in Mali; Panel B: Transmission zone map.

IRS: Indoor Residual Spraying; IPT: Intermittent Preventive Treatment for Pregnant Women; LLIN: Long-Lasting Insecticide Impregnated Mosquito Net; IG2-LLIN: $2^{\text {nd }}$ Generation of Long-Lasting Insecticide Impregnated Mosquito Net; PBO-LLIN: Long-Lasting Insecticide Impregnated Mosquito Net with Piperonyl Butoxide; SMC: Seasonal malaria Chemoprevention for children under 5; MDA: mass drug administration. 
Malaria transmission was very heterogeneous between health districts, with, mainly, two transmission periods ${ }^{21}$ and associated with environmental factors ${ }^{8,21,27,28}$. Malaria transmission is characterized in some countries such as Burkina Faso by three periods of transmission with an intermediate period ${ }^{25}$. In the health districts located in the south with early and abundant rainfall, the period of high transmission began from July to December with a monthly incidence of between 20 and 60 cases per 1,000 personmonths ${ }^{26}$. Health districts in the center, which were in the majority, had the standard high transmission period from July to December with an incidence of between 10 and 30 cases per 1,000 person-months. It represents the majority of health districts in Mali. For the northern health districts, the high transmission period was late, starting in August or even September and ending in January with an incidence drop for some in October. The incidence was often low, less than 5 cases per 1,000 personmonths. These are generally health districts in the north and those located in flooded areas (Dire, Niafunké, Youwarou, Bourem, Gao, Timbuktu) ${ }^{21}$. A cohort study carried out in Bancoumana, around $60 \mathrm{~km}$ south from Bamako, on the incidence of malaria confirmed these results with an incidence of 760 per 1,000 person-years in 2019 in the general population, 530 cases per 1,000 person-years in children under 5 years old and 890 cases per 1,000 for children aged 5 and 10 years old ${ }^{30}$.

Mapping of the adjusted incidence showed that more than a third of the health districts of Mali are in the zone of high transmission with more than 450 cases per 1,000 person-years. These health districts are located in areas of high rainfall, along rivers and flooded areas. Health districts with moderate transmission were generally located in the Sahel with an incidence from 250 to 450 cases per 1,000 person-years. Health districts in areas of low and very low transmission represent $41 \%$. They were located in areas of low rainfall (northern Mali) with a very low population density of less than one habitat per $\mathrm{km}^{2}$. They are located in northern Mali. A Study carried out in Dire, in the Sahelian zone of Mali showed between incidence from 20 to 120 cases per 1,000 person-years ${ }^{21}$. These low transmission areas could be potential candidates for the use of the mass treatment administration strategy to move towards malaria pre-elimination in Mali ${ }^{29}$.

The prevalence results of the DHS only concerned children aged 3-59 months in the different regions. These results are in line with those of the incidence with low malaria prevalence in the northern regions of Mali and the urban area of Bamako. Several studies have confirmed the low prevalence of malaria in these areas due to the low density of malaria vectors linked to low rainfall on the one hand and urbanization on the other. This is the case in other major cities in West Africa ${ }^{31}$. But the low prevalence of malaria does not take into consideration the peri-urban area with their specificity where the prevalence can be high or maintained ${ }^{10}$. Adapted strategies must be made for these suburban areas to control malaria. The percentage of the population living outside a $5-\mathrm{km}$ radius of a health center remains very 
high in the majority of Mali's health districts. It is 40 to $60 \%$ in the health districts of the center of the country and more than $80 \%$ in the northern health districts (Sahara zone).

Alternatives to improve accessibility outside of $5 \mathrm{~km}$, such as the introduction of community health workers and malaria posts, should be developed to compensate for this lack of access to healthcare for children and pregnant women. The involvement of these malaria poste in community diagnosis and treatment of uncomplicated malaria can help in the control of malaria ${ }^{32}$.

DHS mortality data showed a low infant and child mortality rate, under 100 deaths per 1,000 in the northern regions and in Bamako, the capital, compared with 130 deaths per 1,000 in the southern regions (Kayes, Sikasso, Ségou and Mopti). The region of Tombouctou in the north had 131 deaths per 1,000. There was a sharp decline in mortality at the national level between 1987 and 2012, from 247 to 95 deaths per 1,000. It increased in 2018 to 101. This trend is found in the incidence data which have been on the rise in recent years according to the WHO annual report on malaria ${ }^{33}$ and a study carried out on mapping child growth failure ${ }^{34}$.

The available data on malaria vectors was based on research in the sentinel sites. The authorities consider these sites as representative of malaria transmission throughout the country. They carry out clinical, parasitological, and entomological surveillance. Resistance to insecticides has been observed in the majority of A. gambiae vectors, with the exception of two which are pyrimiphos-methyl in Koulikoro ${ }^{35,36}$ and Clothianidins (Neoticotinoid) ${ }^{37}$. This resistance appears to be widespread in Mali and could compromise the effectiveness of vector control. Long-lasting insecticidal nets (LLINs) and indoor residual spraying (IRS) is responsible for $70 \%$ of the reduction in malaria cases ${ }^{38}$. The increase in resistance is pushing countries like Mali to use 2nd generation combination insecticides ${ }^{39}$ and to increase surveillance on insecticides to continue to benefit from their efficacy.

The stratification of malaria in Mali was carried out based on incidence adjusted at the frequentation rate only ${ }^{7}$ then with meteorological and land use data of the health districts ${ }^{40}$. The results of the two approaches were almost similar. The north-south gradient was compromised by the presence of the River Niger in some northern health districts. The zones of very low and low transmission were made up of the health districts of the Sahara strip, part of the Sahel and the capital of Bamako with health districts of Kayes and Yélimané, which have better access to health care. Environmental class 1 and 2 were similar, but surface water (wadis and oasis) was found in some class 2 health districts. These points, which were crossroads, may constitute malaria epidemic foci ${ }^{41}$. These epidemics were described in the studies in the Sahara of Mali ${ }^{42,43}$. Class 3 was located south of the Sahara and had more malaria risk than Class 1 and 2 due to the presence of the river. Class 5 was similar to class 3 in terms of incidence but the presence of low vegetation. This was a Saharan area with epidemic potential ${ }^{44}$. The health districts of the moderate transmission zone were located in the Sahelian zone of Mali, and the zone of high malaria transmission was located in the south, the Sudan zone. Class 4 , where the majority of health 
districts were located, was the malaria endemic area of Mali. The risk increased due to the river and the cultivation areas in the inner delta. Consequently, the Niger River have an important role in malaria transmission in Mali that must be considered in the implementation of control interventions ${ }^{45-47}$. Environmental class 6 was located in the Sahelian zone with an environmental risk as in class 4, but transmission was low due to urbanization and better access to care: Bamako and the health districts of Kayes, and Yélimané. The two latter have many health care structures through the investment of expatriates.

Based on the WHO global technical guidelines 2016-2030, national guidelines and the different maps and strates (incidences, environment, entomology, access to care), different interventions have been proposed together with the National Malaria Control Programme. In the extreme north, experiencing very low incidences and showing very few risk factors, the strategy should based on a strengthened epidemiological surveillance system for the early detection of epidemics and molecular surveillance ${ }^{48,49}$, aiming at developing reactive interventions including local IRS, distribution of PBO-LLIN and locally targeted Mass drug administrations. Countries such as Algeria and Mauritania that border health districts in this zone have all eradicated malaria ${ }^{50,51}$. By keeping up the epidemic surveillance efforts that have been started, Mali will be able to rapidly reach the pre-elimination phase in these areas. However, epidemiological and molecular surveillance will be crucial with the resurgence of Plasmodium vivax and Plasmodium malaria ${ }^{52,53}$. Diagnosis and treatment will be improved with the introduction of multispecies rapid diagnostic tests (RDTs) to detect other species outside of Plasmodium falciparum ${ }^{54,55}$.

In the low transmission area (northern part), with the presence of environmental risk factors (mainly around the Niger River), even if the improvement of the epidemiological surveillance system is necessary, the strategy should be mainly based on malaria posts, training, and supervising, community health workers on malaria detection and treatment (together with periodic prevention actions). In this area, PBO-LLIN distribution, IPT and SMC should be reinforced. New targeted strategies, adapted to local context, may be applied targeting place and period in order to limit malaria transmission, in a bottle-neck approach ${ }^{56}$.

411 In the moderate transmission area (mainly in the central Mali), the control strategy should be based on strengthening access to rapid diagnosis and treatment, improving local health center, and developing malaria post in the most remote areas. The prevention strategies, IPT, IRS, SMC and PBO-LLIN distribution should be continued, and the extension of SMC to children aged from 5 to 10 years is being considered. Furthermore, in this moderate transmission area, the assessment of hotspot of malaria transmission during the low transmission season should be proposed in order to develop local reactive interventions during this period, adapted to the local context (e.g. dam, mine, etc.).

418 Finally, in the high transmission area (mainly in the southern part), the control strategy should be also 419 based on strengthening access to rapid diagnosis and treatment, improving local health center, and 
developing malaria post in the most remote areas. The prevention strategies, IPT, IRS and SMC should be continued, and the extension of SMC to children aged from 5 to 10 years is being considered. IG2LLIN distributions should be developed, due to the spread of insecticide resistance ${ }^{57-59}$.

The main limitation of this study was the choice of the health district scale. Malaria transmission is heterogeneous within a health district (several health areas), and the social and behavioral characteristics of the inhabitants may hinder unsuitable national strategies.

\section{Conclusion}

Considering the environmental risk and malaria incidence, classes of malaria risk have been selected to guide interventions of National Malaria Control Programme. Interventions were proposed according to environmental class, level of malaria incidence, insecticide resistance and level of access to care. It made it possible to move towards targeting priority interventions by strata.

Due to climate change, our approach is dynamic that has to be periodically revised, to account for environmental, sociological, and epidemiological changes. It provides the starting point for a phase towards pre-elimination in optimizing and targeting control strategies.

\section{Availability of data and materials}

The data and background maps are available at the level of the authors and the NMCP of Mali. Anyone wishing to consult or use these data are requested to contact us.

\section{Consent to publication:}

438 Not applicable.

\section{Acknowledgments}

440 We would like to thank the National Malaria Control Program (NMCP). Our acknowledgment goes to 441 Abdoulaye Ongoiba at MRTC, IECR, USTTB, Mali for providing the training on ArcGIS, Jennifer L. 442 Kwan, PhD. at NIAID, NIH, US for facilitating the acquisition of the ArcGIS and the Health and Human 443 Services Grant Program at ESRI for providing the ArcGIS desktop software license and training to Mali 444 Ministry of Health used here for malaria data mapping.

446 Authors' contribution: MC and IS designed the study; VS, MM and LS collected the field study 447 coordinated by MC; MC, JG and IS developed the statistical analysis plan with LS, MD, AK 
$\mathrm{O}, \mathrm{CSB}, \mathrm{MDB}, \mathrm{AMD}, \mathrm{SD}$, and MBC. MC carried out the statistical analysis under the supervision of IS, JL and JG. MC performed the cartographic analysis with the participation of AMD. IS. JG, DT, IC, BS, and MS participated in the statistical analysis and validated results. MC, IS and JG wrote the manuscript. All authors participated and agreed to the published version of the manuscript.

452

453

454

455

456

457

458

459

460

461

462

463

464

465

466

467

468

469

470

471

472

473

474

\section{Conflicts of Interest:}

The authors declare no conflicts of interest.

\section{Funding:}

WHO offices Geneva and Bamako supported the research collaboration. This work was also supported by a French ARTS grant from the French Research Institute for Development France (IRD) and by the JEAI (young team associated with the IRD) "Spatiotemporal Dynamics of Malaria Transmission in Changing Environments (DynaSTEC). The Non-Governmental Organization Prospective et Cooperation also provided technical support.

\section{References}

1. DGSHP - Mali. Annuaire Statistique du Système Local d'Information Sanitaire du Mali 2018. (2018).

2. Les aspects parasitologiques de l'épidémiologie du paludisme dans le Sahara malien - fdi:31747 Horizon. https://www.documentation.ird.fr/hor/fdi:31747.

3. Niangaly, A. et al. Plasmodium vivax Infections over 3 Years in Duffy Blood Group Negative Malians in Bandiagara, Mali. Am. J. Trop. Med. Hyg. 97, 744-752 (2017).

4. Bernabeu, M. et al. Plasmodium vivax malaria in Mali: a study from three different regions. Malar. J. 11, 405 (2012).

5. Coetzee, M. et al. Anopheles coluzzii and Anopheles amharicus, new members of the Anopheles gambiae complex. Zootaxa 3619, 246-274 (2013).

6. Cisse, M. B. M. et al. Characterizing the insecticide resistance of Anopheles gambiae in Mali. Malaria Journal 14, 327 (2015).

7. World Health Organization. Global Technical Strategy for Malaria 2016-2030. https://www.who.int/malaria/publications/atoz/9789241564991/en/ (2015). 
8. Ateba, F. F. et al. Spatio-Temporal Dynamic of Malaria Incidence: A Comparison of Two Ecological Zones in Mali. International Journal of Environmental Research and Public Health 17, $4698(2020)$.

9. Coulibaly, D. et al. Spatio-Temporal Dynamics of Asymptomatic Malaria: Bridging the Gap Between Annual Malaria Resurgences in a Sahelian Environment. Am. J. Trop. Med. Hyg. 97, 1761-1769 (2017).

10. Sissoko, M. S. et al. Temporal dynamic of malaria in a suburban area along the Niger River. Malaria Journal 16, (2017).

11. M. Keïta, Baber N. SogobaH. M. MaïgaM’B. Diallo S. Doumbia, S. F. Traoré. Transmission vectorielle du paludisme dans un village du bord du fleuve Niger et son hameau de pêche (Kéniéroba et Fourda, Mali) | SpringerLink. 107, 356-368 (2014).

12. Saugeon, C., Baldet, T., Akogbeto, M. \& Henry, M. C. Will climate and demography have a major impact on malaria in sub-Saharan Africa in the next 20 years. Med Trop (Mars) 69, 203-207 (2009).

13. Diakalia, K., Drissa, C. \& Ogobara, D. PNLP, MRTC and INFORM (2015). An epidemiological profile of malaria in Mali. A report prepared for the Ministry of Health, Mali, the Roll Back Malaria Partnership and the Department for International Development, UK. February, 2015. 88 http://www.inform-malaria.org/wp-content/uploads/2015/03/Mali-Malaria-Epi-ProfileReport_030315.pdf (2015).

14. Wetlands International Afrique. Rapport annuel 2019. Wetlands International Afrique https://africa.wetlands.org/publications/rapport-annuel-2019/.

15. Cisse, M. B. M. et al. Characterizing the insecticide resistance of Anopheles gambiae in Mali. Malar $J$ 14, (2015).

16. Huffman, G.J.; Stocker, E.F.; Bolvin, D.T.; Nelkin, E.J.; Jackson Ta. NASA 2019. GPM IMERG Early Precipitation L3 1 day 0.1 degree x 0.1 degree V06, Edited by Andrey Savtchenko, Greenbelt, MD, Goddard Earth Sciences Data and Information Services Center (GES DISC) 2019, Accessed: 10.5067/GPM/IMERGDE/DAY/06. (2020).

17. Buchhorn, M. et al. Copernicus Global Land Cover Layers-Collection 2. Remote Sensing 12, 1044 (2020). 
18. Abdoulaye Dao. Surveillance de la résistance des vecteurs du paludisme aux insecticides dans cinq sites sentinelles au Mali, Financé par PSI-Mali - Thèse de Pharmacie. (2020).

19. Keïta, M. et al. Susceptibilité d'Anopheles gambiae sensu lato aux insecticides communément utilisés dans la lutte antivectorielle au Mali. Bull. Soc. Pathol. Exot. 109, 39-45 (2016).

20. Zhang, N. R. \& Siegmund, D. O. A modified Bayes information criterion with applications to the analysis of comparative genomic hybridization data. Biometrics 63, 22-32 (2007).

21. Cissoko, M. et al. Geo-Epidemiology of Malaria at the Health Area Level, Dire Health District, Mali, 2013-2017. Int J Environ Res Public Health 17, (2020).

22. Gaudart, J. et al. Space-time clustering of childhood malaria at the household level: a dynamic cohort in a Mali village. BMC Public Health 6, 286 (2006).

23. Husson, François, Sébastien Lê, and Jérôme Pagès. Analyse De Données Avec R. Presses universitaires de Rennes. (2009).

24. Piarroux, M. et al. Landscape and climatic characteristics associated with human alveolar echinococcosis in France, 1982 to 2007. Euro Surveill 20, (2015).

25. Ouedraogo, B. et al. Spatio-temporal dynamic of malaria in Ouagadougou, Burkina Faso, 20112015. Malaria Journal 17, (2018).

26. Wagman, J. et al. An observational analysis of the impact of indoor residual spraying with nonpyrethroid insecticides on the incidence of malaria in Ségou Region, Mali: 2012-2015. Malar J 17, 19 (2018).

27. Abiodun, G. J. et al. Exploring the Influence of Daily Climate Variables on Malaria Transmission and Abundance of Anopheles arabiensis over Nkomazi Local Municipality, Mpumalanga Province, South Africa. J Environ Public Health 2018, 3143950 (2018).

28. Rouamba, T. et al. Socioeconomic and environmental factors associated with malaria hotspots in the Nanoro demographic surveillance area, Burkina Faso. BMC Public Health 19, 249 (2019).

29. World Health Organization. Mass drug administration for falciparum malaria: a practical field manual. 112 (2017) doi:https://apps.who.int/iris/handle/10665/259367. 
30. Coulibaly, D. et al. A Decline and Age Shift in Malaria Incidence in Rural Mali following Implementation of Seasonal Malaria Chemoprevention and Indoor Residual Spraying. Am J Trop Med Hyg (2021) doi:10.4269/ajtmh.20-0622.

31. Baragatti, M. et al. Social and environmental malaria risk factors in urban areas of Ouagadougou, Burkina Faso. Malar J 8, 13 (2009).

32. Hamer, D. H. et al. Quality and safety of integrated community case management of malaria using rapid diagnostic tests and pneumonia by community health workers. Pathog Glob Health 106, 3239 (2012).

33. WHO: World Health Organization, World malaria report 2018. https://www.who.int/malaria/publications/world-malaria-report-2018/report/en/ (2018).

34. Osgood-Zimmerman, A. et al. Mapping child growth failure in Africa between 2000 and 2015. Nature 555, 41-47 (2018).

35. Shaffer, J. G. et al. Clustering of asymptomatic Plasmodium falciparum infection and the effectiveness of targeted malaria control measures. Malaria Journal 19, 33 (2020).

36. Coulibaly, B. et al. Malaria vector populations across ecological zones in Guinea Conakry and Mali, West Africa. Malar. J. 15, 191 (2016).

37. Wagman, J. et al. Combining next-generation indoor residual spraying and drug-based malaria control strategies: observational evidence of a combined effect in Mali. Malar J 19, 293 (2020).

38. Musiime, A. K. et al. Impact of vector control interventions on malaria transmission intensity, outdoor vector biting rates and Anopheles mosquito species composition in Tororo, Uganda. Malaria Journal 18, 445 (2019).

39. Wagman, J. et al. An observational analysis of the impact of indoor residual spraying with nonpyrethroid insecticides on the incidence of malaria in Ségou Region, Mali: 2012-2015. Malar J 17, 19 (2018).

40. Thawer, S. G. et al. Sub-national stratification of malaria risk in mainland Tanzania: a simplified assembly of survey and routine data. Malaria Journal 19, 177 (2020).

41. Deida, J. et al. Oasis Malaria, Northern Mauritania1. Emerg Infect Dis 25, 282-289 (2019). 
42. Dombo, O.; Sankare, O.; Toure, Y. Malaria in the Sahel: the example of Mali. Maladies Tropicales transmissibles, Ed. John Libbey Eurotext 11-32 (1989).

43. Doumbo, O. et al. Parasitological aspects of the epidemiology of malaria in the Malian Sahara. Médecine d'Afrique Noire 5 (1991).

44. Diakité, S. A. S. et al. A comprehensive analysis of drug resistance molecular markers and Plasmodium falciparum genetic diversity in two malaria endemic sites in Mali. Malaria Journal 18, 361 (2019).

45. Sissoko, M. S. et al. Malaria incidence in relation to rice cultivation in the irrigated Sahel of Mali. Acta Tropica 89, 161-170 (2004).

46. Dolo, G. et al. Malaria transmission in relation to rice cultivation in the irrigated Sahel of Mali. Acta Tropica 89, 147-159 (2004).

47. Jarju, L. B. et al. Agriculture and the promotion of insect pests: rice cultivation in river floodplains and malaria vectors in The Gambia. Malaria Journal 8, 170 (2009).

48. Dayananda, K. K., Achur, R. N. \& Gowda, D. C. Epidemiology, drug resistance, and pathophysiology of Plasmodium vivax malaria. J Vector Borne Dis 55, 1-8 (2018).

49. Erdman, L. K. \& Kain, K. C. Molecular diagnostic and surveillance tools for global malaria control. Travel Med Infect Dis 6, 82-99 (2008).

50. Jesus, E. I. G. de. Algeria and Argentina declared malaria-free. Nature (2019) doi:10.1038/d41586019-01684-8.

51. Ba, O., Ouldabdallahi, M., Koïta, M., Sy, O. \& Dahdi, S. A. Epidemiology of malaria and elimination prospects in Maghreb Countries. Tunis Med 96, 590-598 (2018).

52. Koita, O. A. et al. Effect of seasonality and ecological factors on the prevalence of the four malaria parasite species in northern mali. J Trop Med 2012, 367160 (2012).

53. Bernabeu, M. et al. Plasmodium vivax malaria in Mali: a study from three different regions. Malaria Journal 11, 405 (2012).

54. Mukkala, A. N. et al. An Update on Malaria Rapid Diagnostic Tests. Curr Infect Dis Rep 20, 49 (2018). 
55. Mosquera-Romero, M., Zuluaga-Idárraga, L. \& Tobón-Castaño, A. Challenges for the diagnosis and treatment of malaria in low transmission settings in San Lorenzo, Esmeraldas, Ecuador. Malar $J$ 17, 440 (2018).

56. Landier, J., Rebaudet, S., Piarroux, R. \& Gaudart, J. Spatiotemporal analysis of malaria for new sustainable control strategies. BMC Med 16, 226 (2018).

57. Tandina, F. et al. Mosquitoes (Diptera: Culicidae) and mosquito-borne diseases in Mali, West Africa. Parasit Vectors 11, 467 (2018).

58. A, S. et al. Anopheles gambiae (s.l.) exhibit high intensity pyrethroid resistance throughout Southern and Central Mali (2016-2018): PBO or next generation LLINs may provide greater control. Parasit Vectors 13, 239-239 (2020).

59. Bah, M. et al. Combining next-generation indoor residual spraying and drug-based malaria control strategies: Observational evidence of a combined effect in Mali. (2020) doi:10.1186/s12936-02003361-y. 


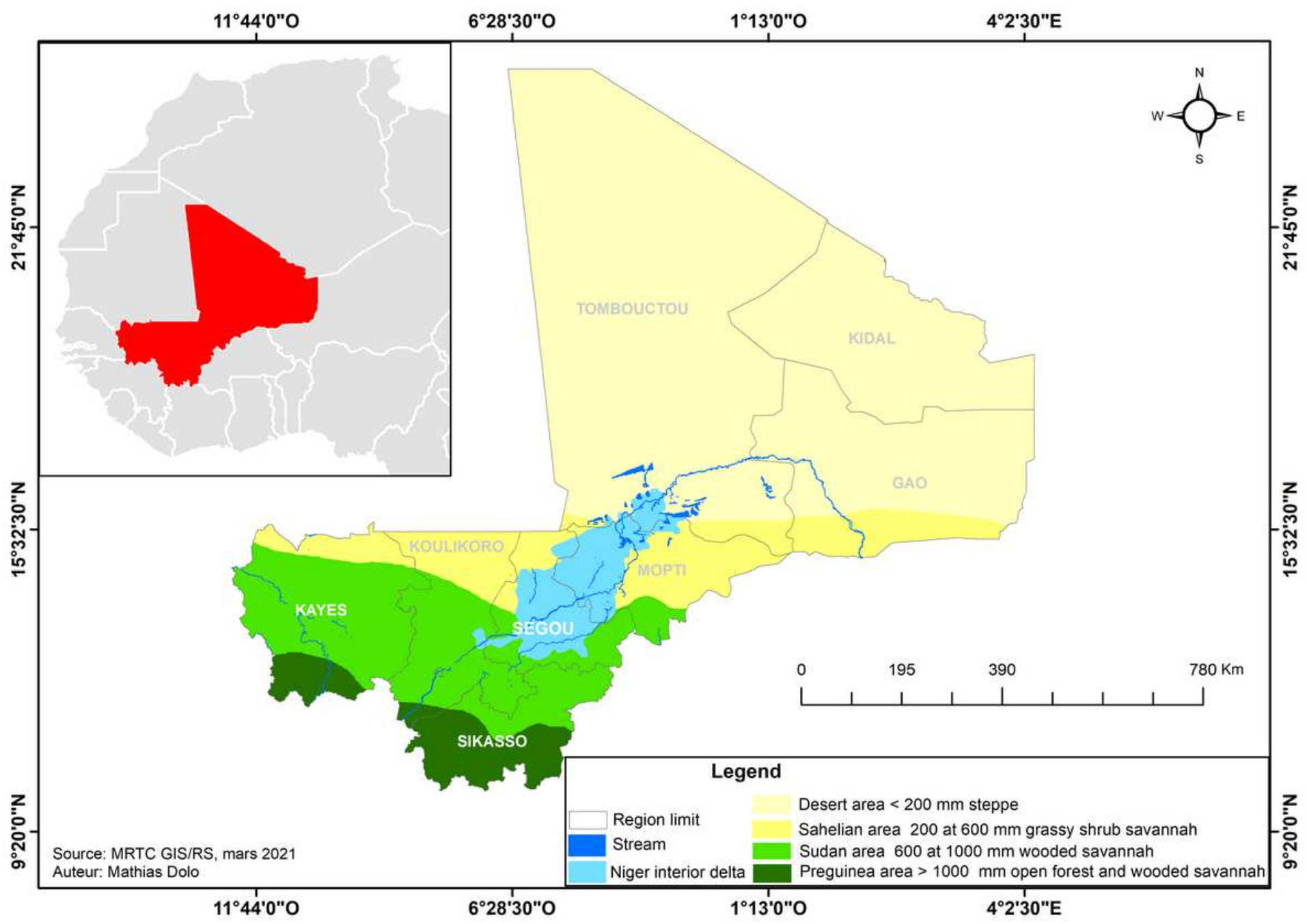

\section{Figure 1}

Different ecoclimatic zones in Mali (Source: MRTC GIS/RS). 


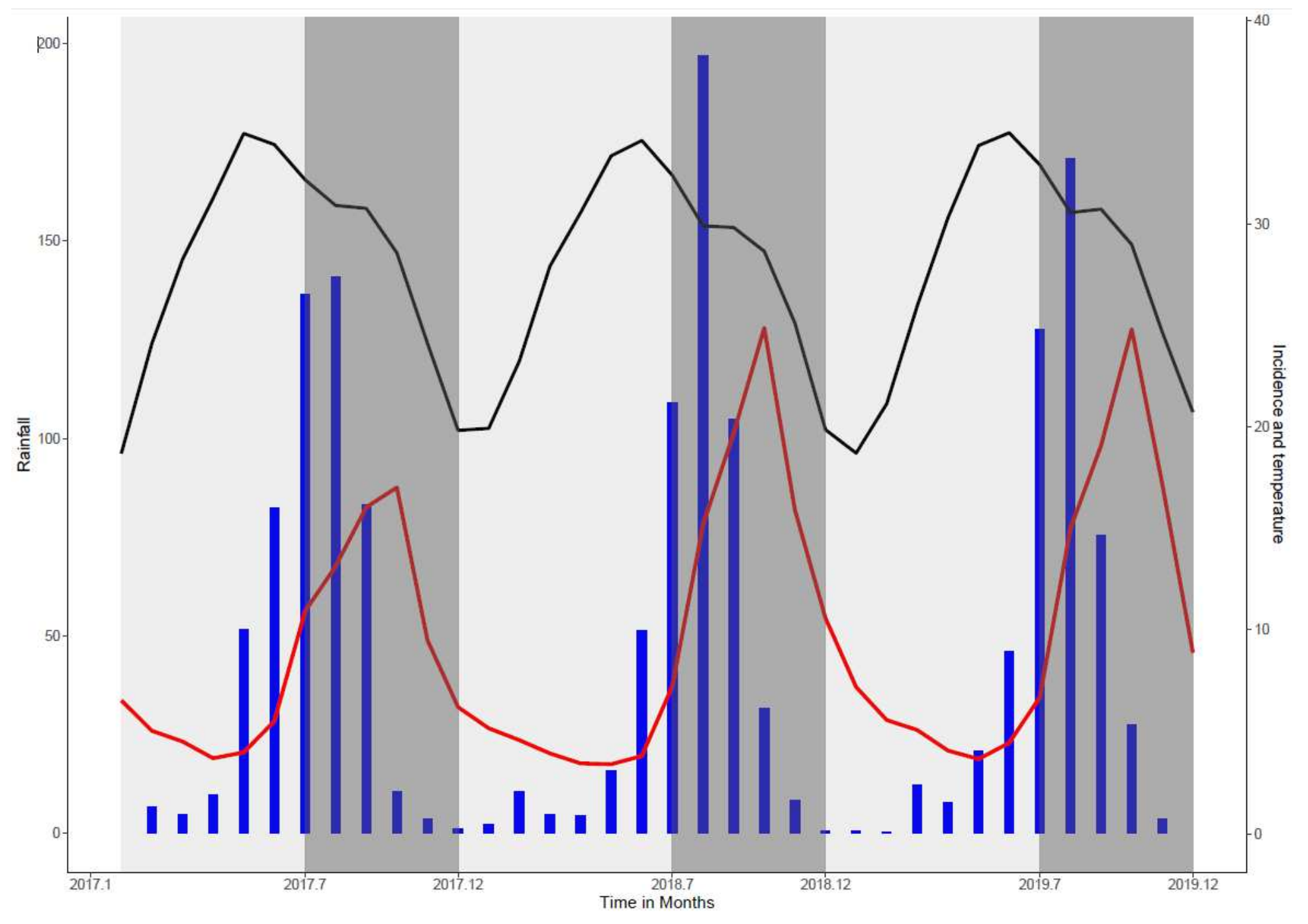

Figure 2

Malaria incidence time series, 2017-2019. Grey band: periods of high malaria transmission (according to the change point analysis); Blue bars: rainfall (left y-axis, $\mathrm{mm}$ ); Red curve: Malaria incidence (y-right axis, cases/person-month); Black curve: average monthly temperature in a black (y right axis, ${ }^{\circ} \mathrm{C}$ ). 

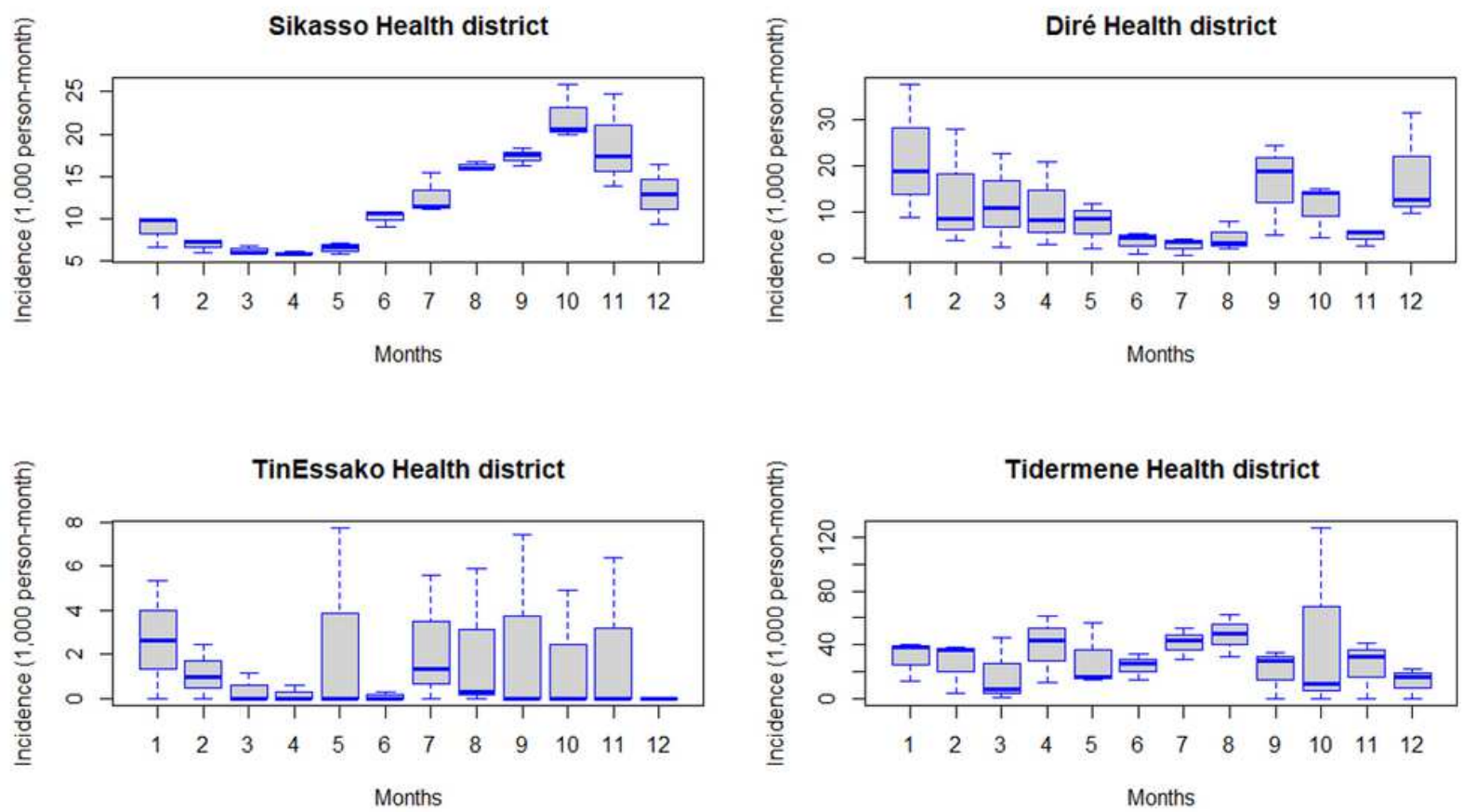

\section{Figure 3}

synthetic indices from the Principal Component Analysis (PCA) of the different meteorological factors.

\section{Panel a}

Panel b
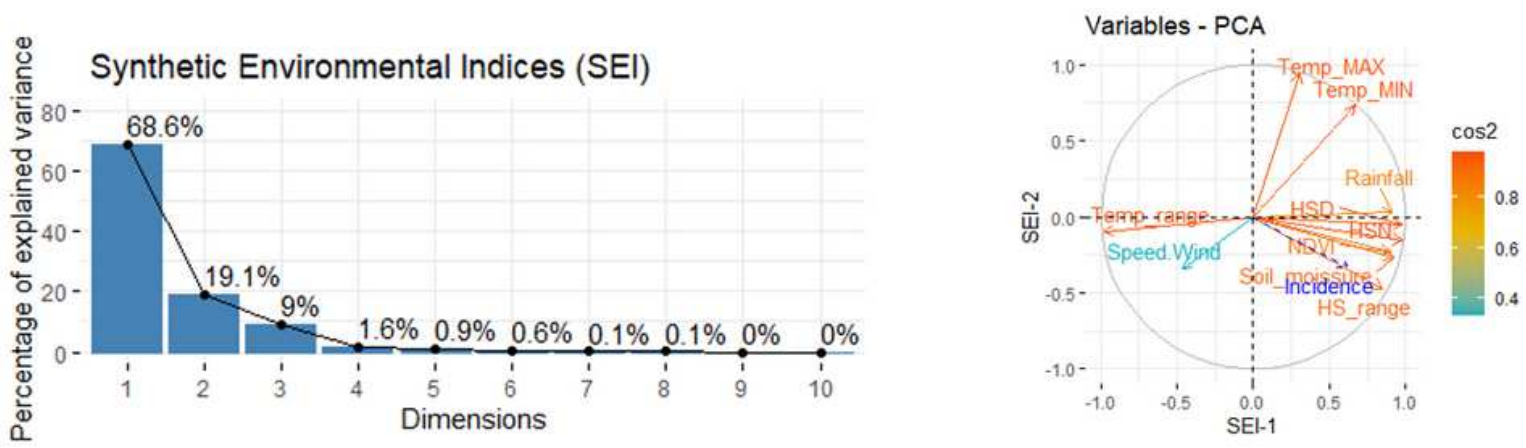
Changes in malaria incidence as a function of synthetic environmental indices; GAM multivariate analysis.

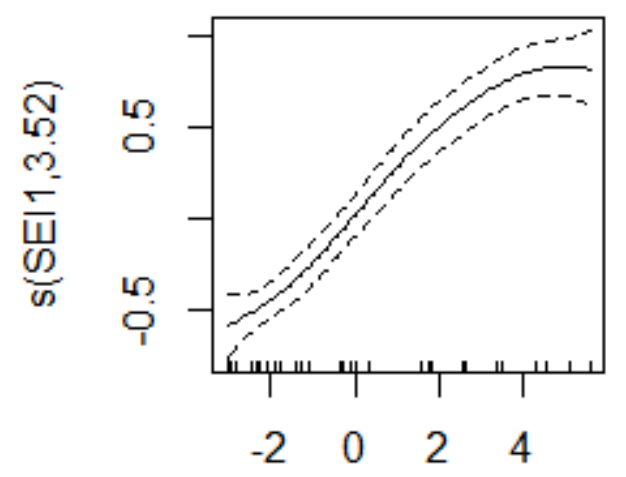

Rainfall, NDVI, relative humidity, soil moisture

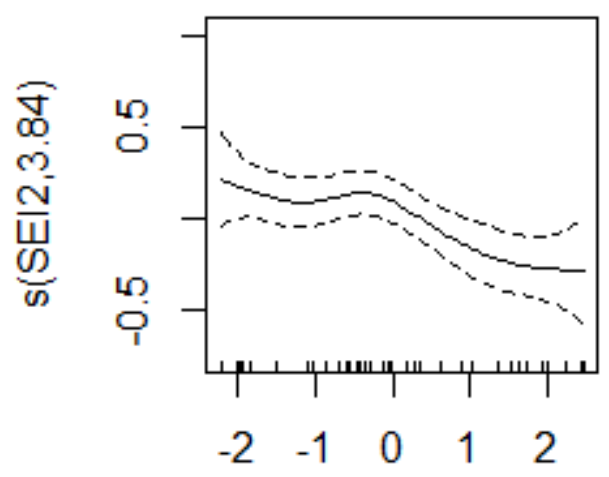

Maximum temperature

\section{Figure 5}

Annual malaria incidence at the health district level, adjusted for health facility access, Mali, 2019. 


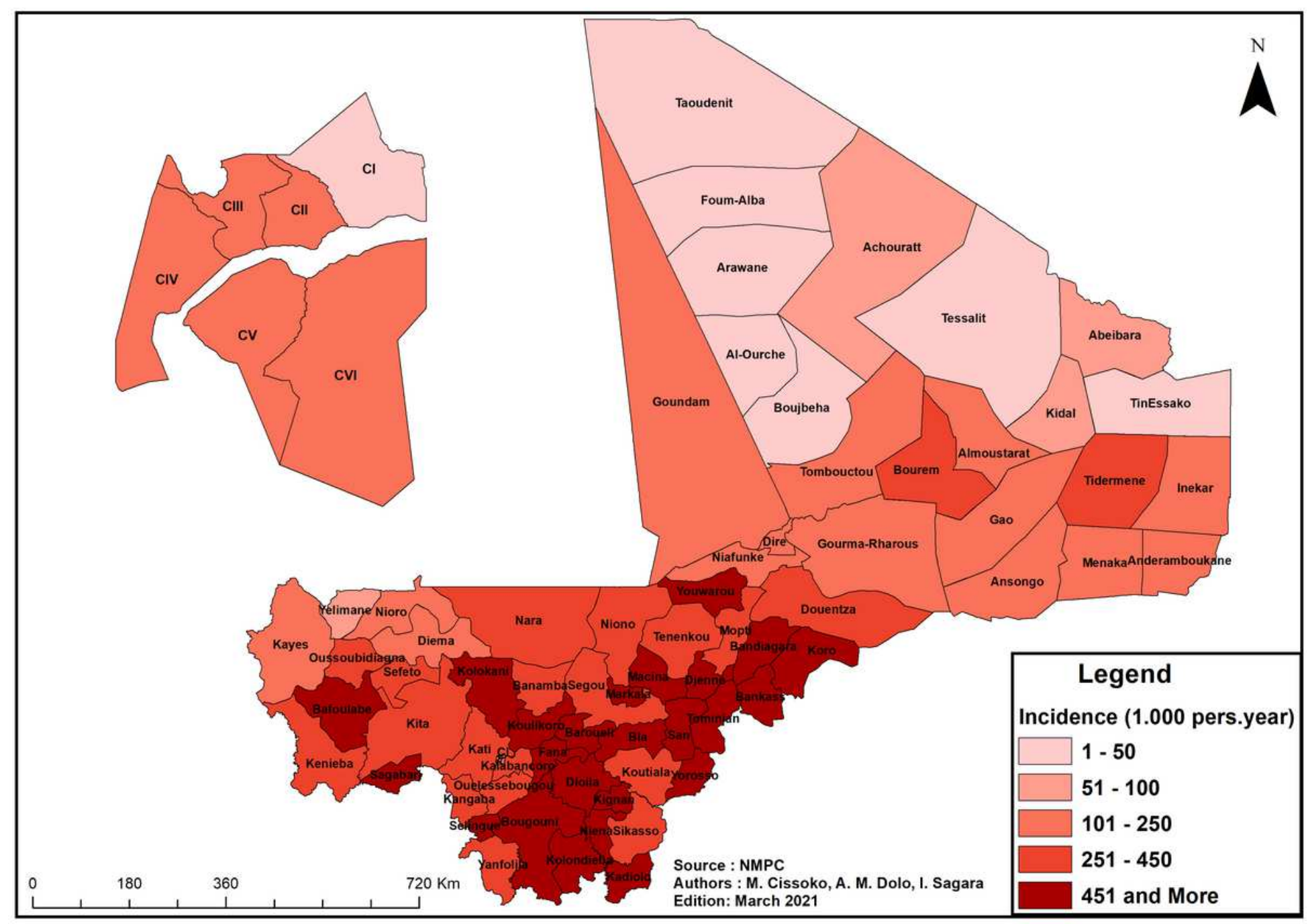

Figure 6

Map of average annual rainfall from 2017 to 2019 by health district in Mali. The average annual rainfall from 2017 to 2019 varies from less than $200 \mathrm{~mm}$ in the desertic zone to more than $1100 \mathrm{~mm}$ in the Sudano-Guinean zone, with a clear north to south trend. Within the 75 health districts, 17 showed an average rainfall of less than $200 \mathrm{~mm}$ (desertic zone), 20 showed an average rainfall between 200 and $600 \mathrm{~mm}$ (Sahelian zone), 10 showed an average rainfall between 600 and $800 \mathrm{~mm}, 21$ showed an average rainfall between 800 and $1100 \mathrm{~mm}$ (Sudanese) and 7 health districts showed an average rainfall above $1100 \mathrm{~mm}$ (Sudano-Guinean zone). 


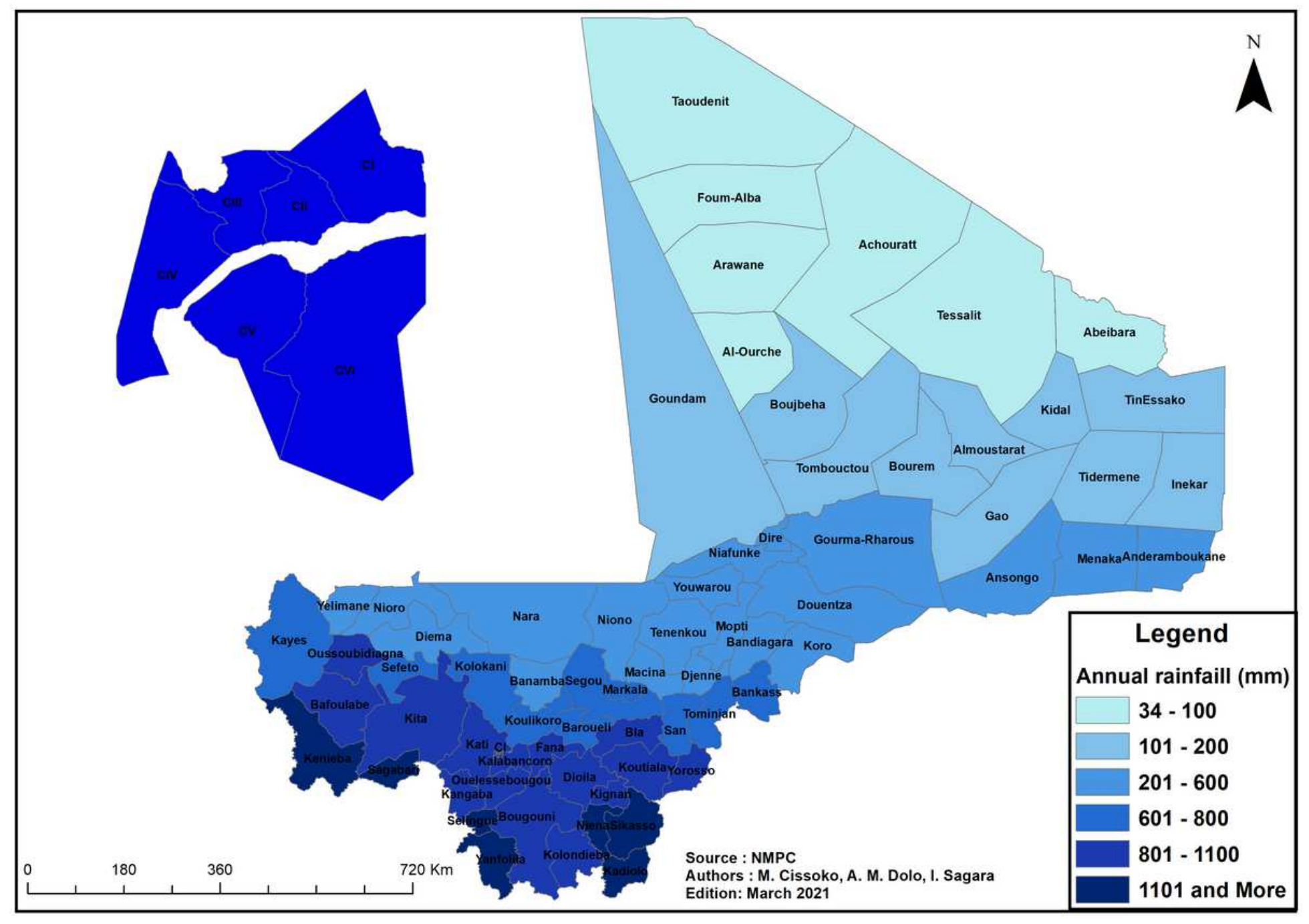

Figure 7

Percentage of population outside at 5-km radius of a health facility in Mali 2019 


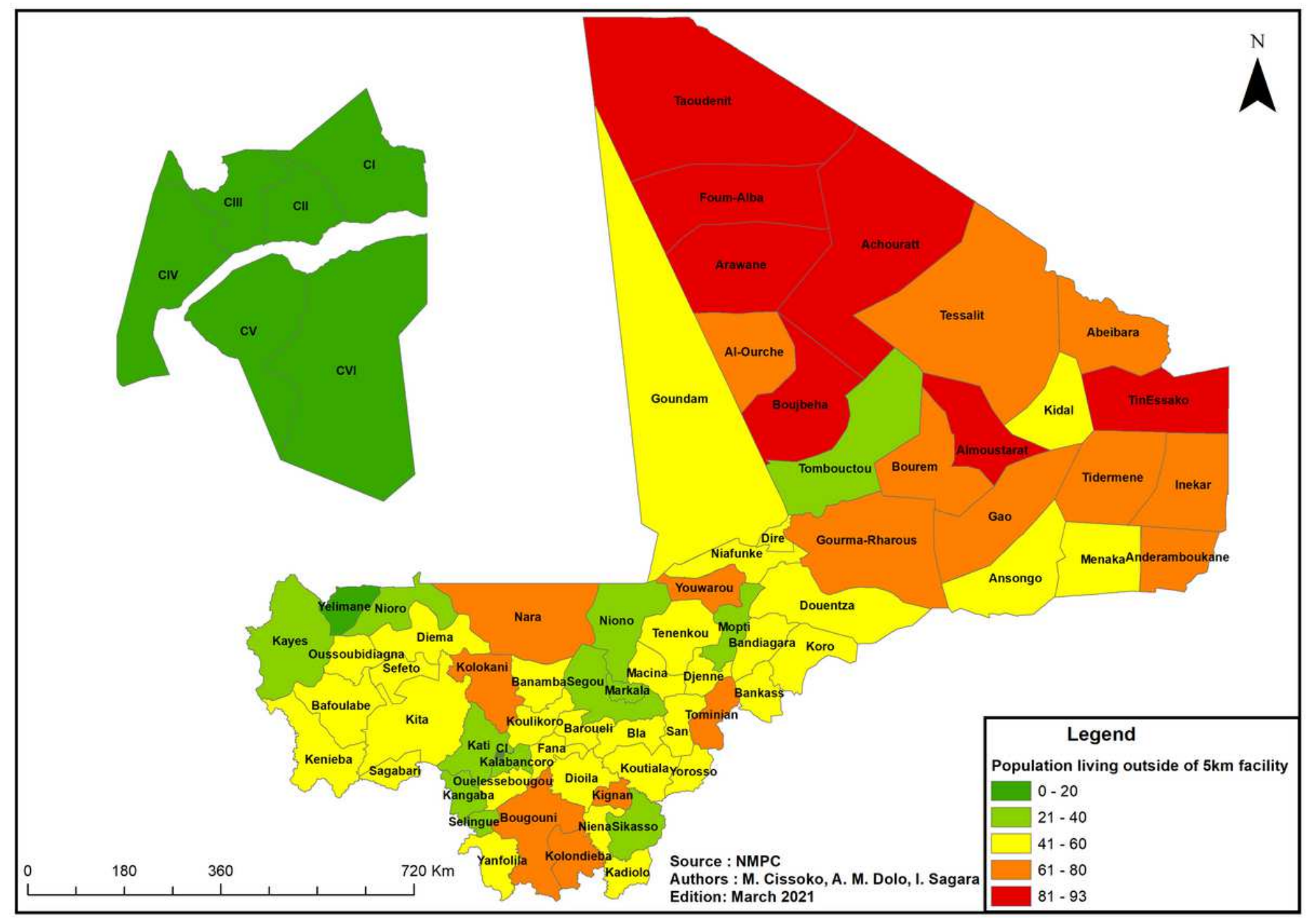

Figure 8

Malaria prevalence map of children aged 6-59 months according to DHS VI, Mali 2018. 


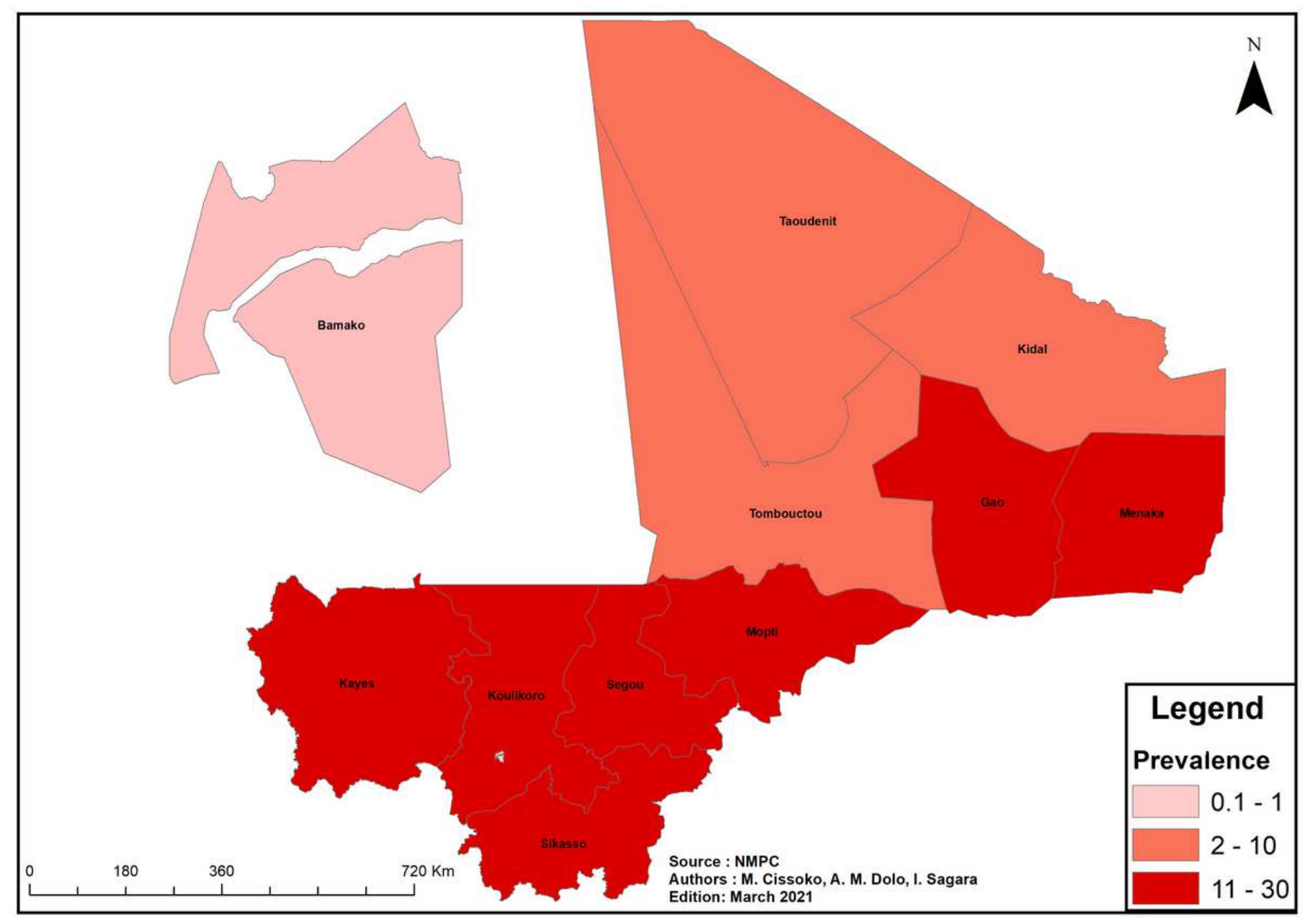

Figure 9

Map of mortality of children under 5 years old from DHS 2018 survey in Mali. 


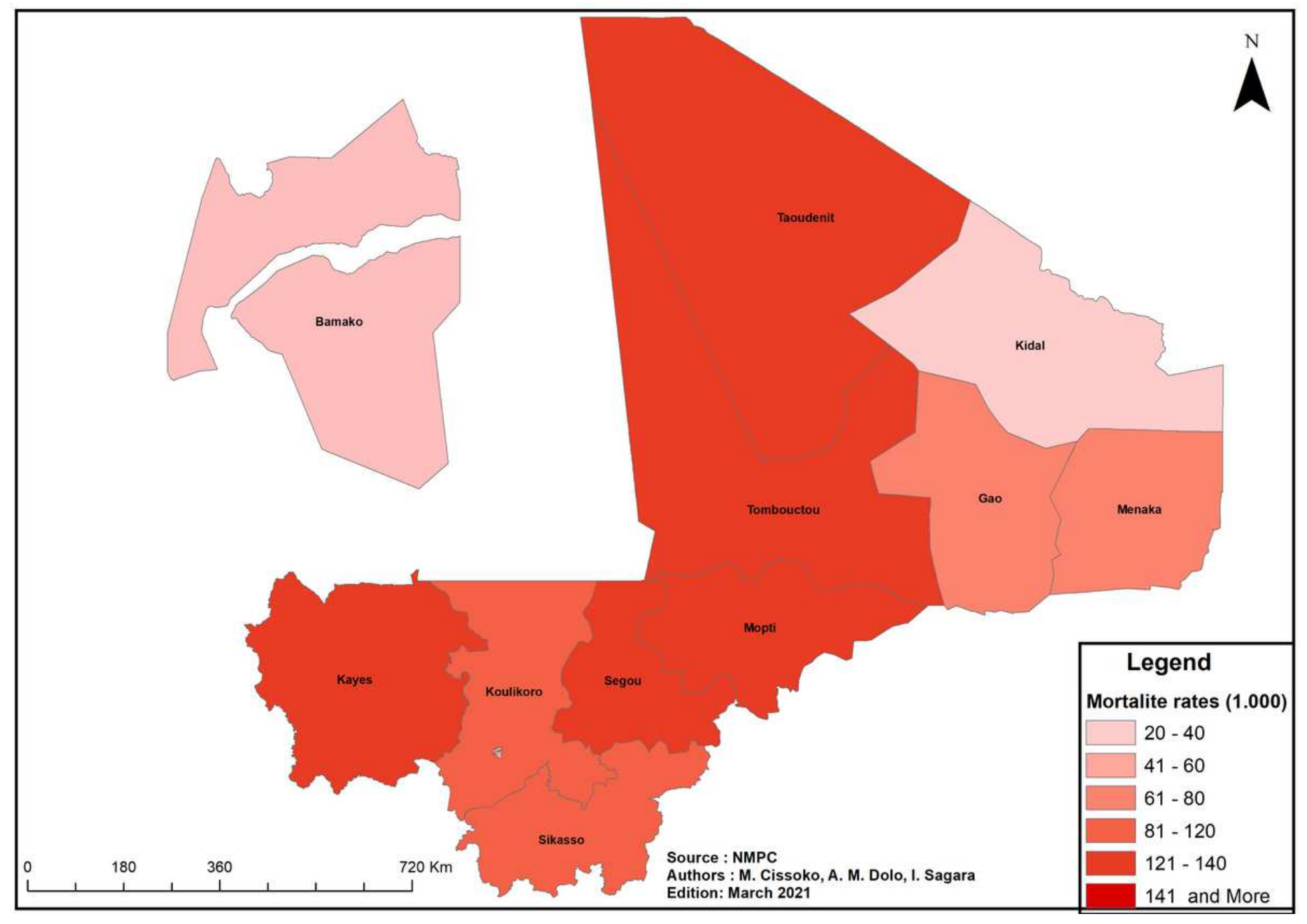

Figure 10

Malaria vector distribution map, 2010 - 2019. The sector diagrams show the presence of the different species. 


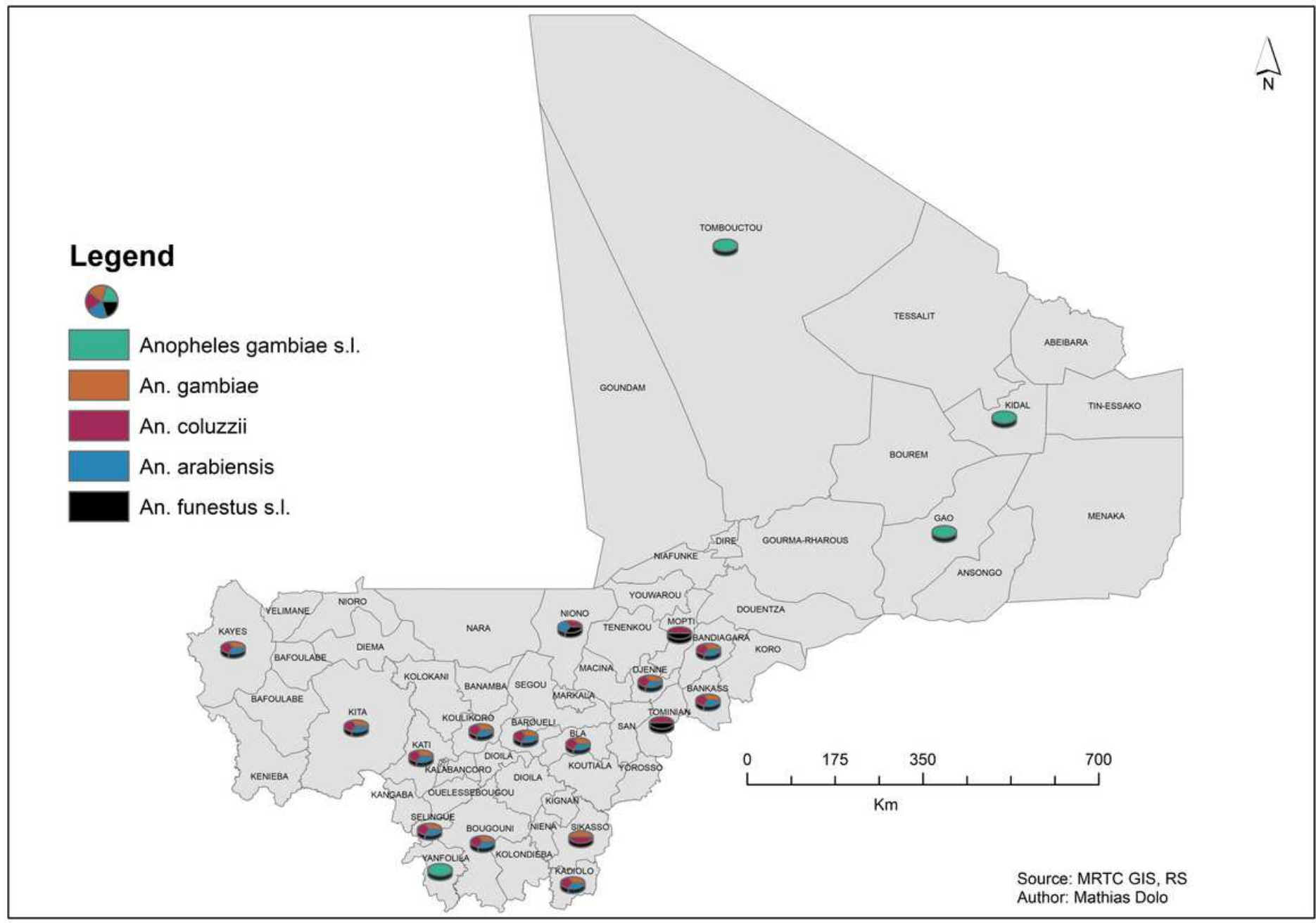

\section{Figure 11}

Map distribution of resistance of Anopheles gambiae s.l., a major malaria vector to different insecticides from 2010 to 2019 in Mali. Red dots show the presence of insecticide resistance in the health district, yellow dots show moderate sensitivity (below 90\%) and green dots show a high sensitivity of major vectors to insecticide. 


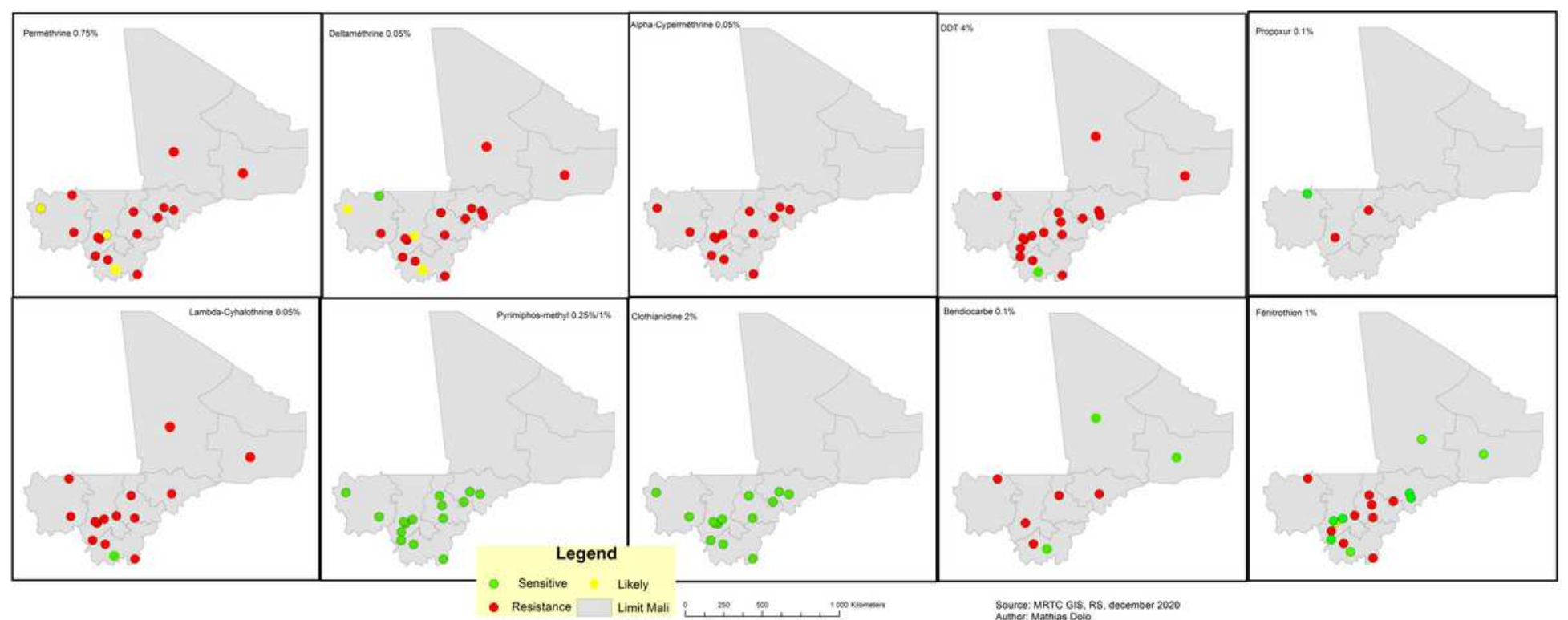

Figure 12

Environmental supervised classification of malaria in Mali (CART). Class 1: Very low vegetation and no surface water; Class 2: Very low vegetation around oases or wadis; Class 3: Low vegetation around the northern part of the Niger River; Class 4: higher vegetation index, low night and day temperatures $\left(<22^{\circ} \mathrm{C}\right.$, $<37.47^{\circ} \mathrm{C}$, respectively); Class 5 : higher vegetation index, high daily temperature $\left(>37.47^{\circ} \mathrm{C}\right)$ and low night temperature $\left(<22^{\circ} \mathrm{C}\right)$; Class 6 : higher vegetation index, high night temperature $\left(>22^{\circ} \mathrm{C}\right)$. 


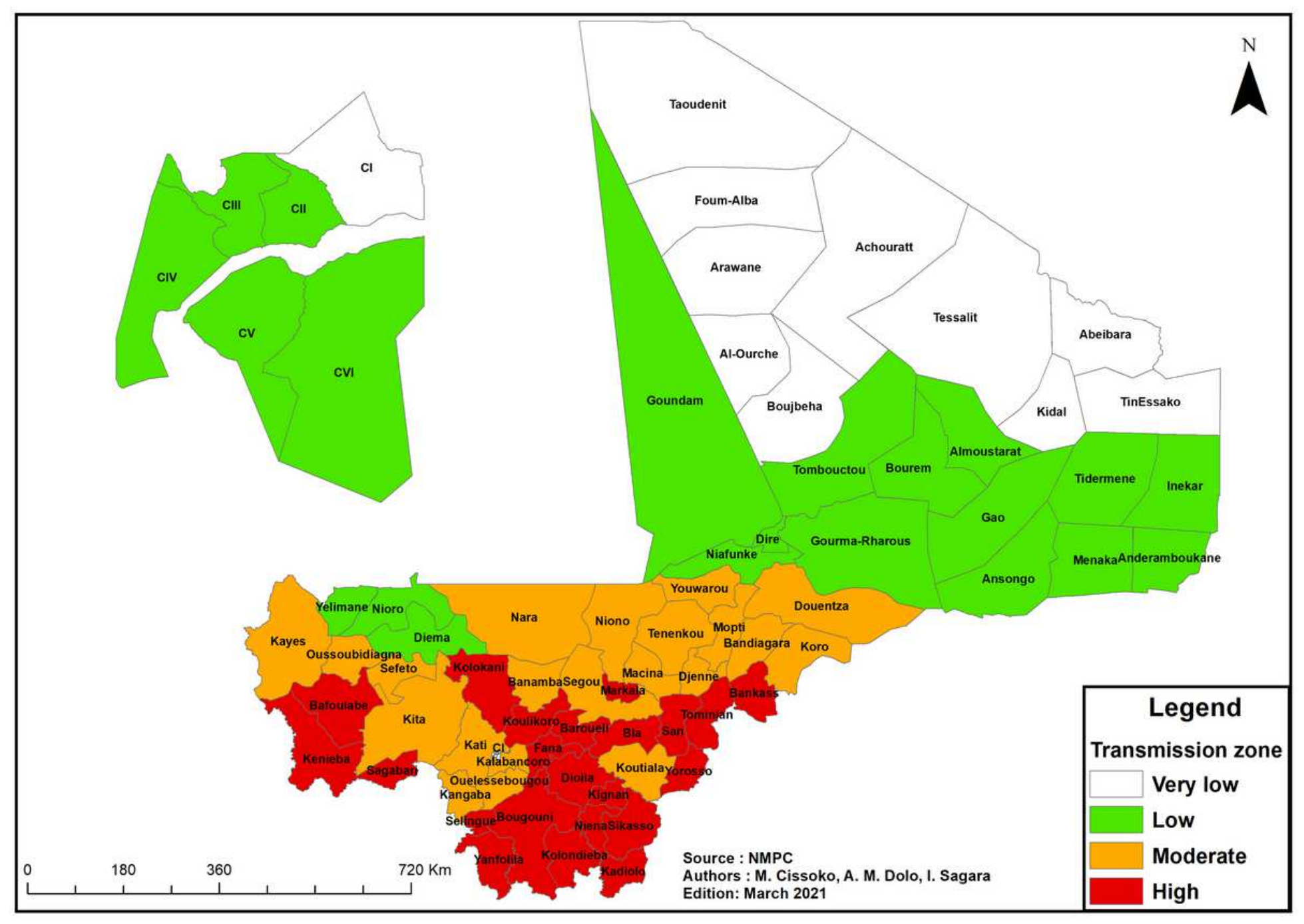

Figure 13

Malaria transmission zones in Mali according to adjusted incidence. Panel A: eligible interventions according to strata and information on insecticide resistance in Mali; Panel B: Transmission zone map 

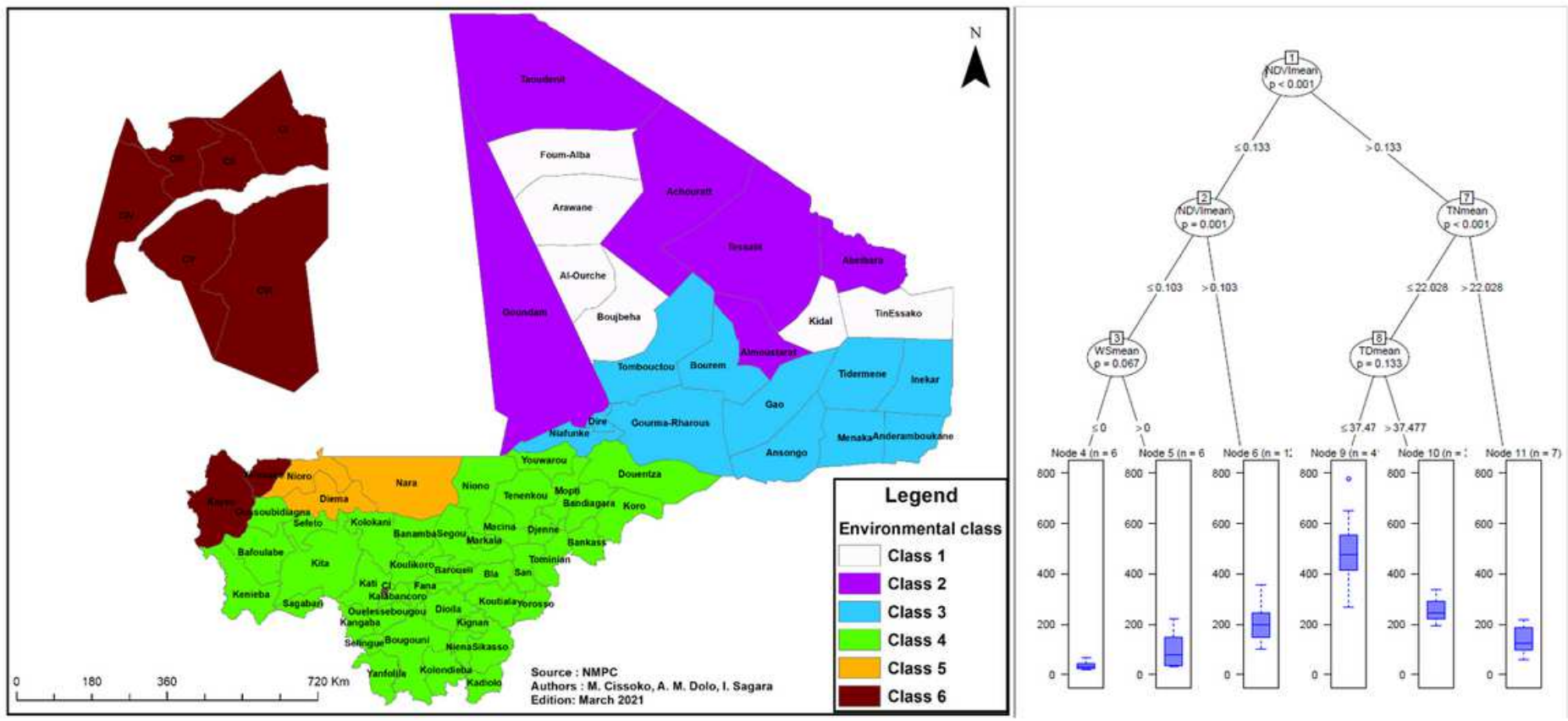

\section{Figure 14}

Environmental class of malaria in Mali.

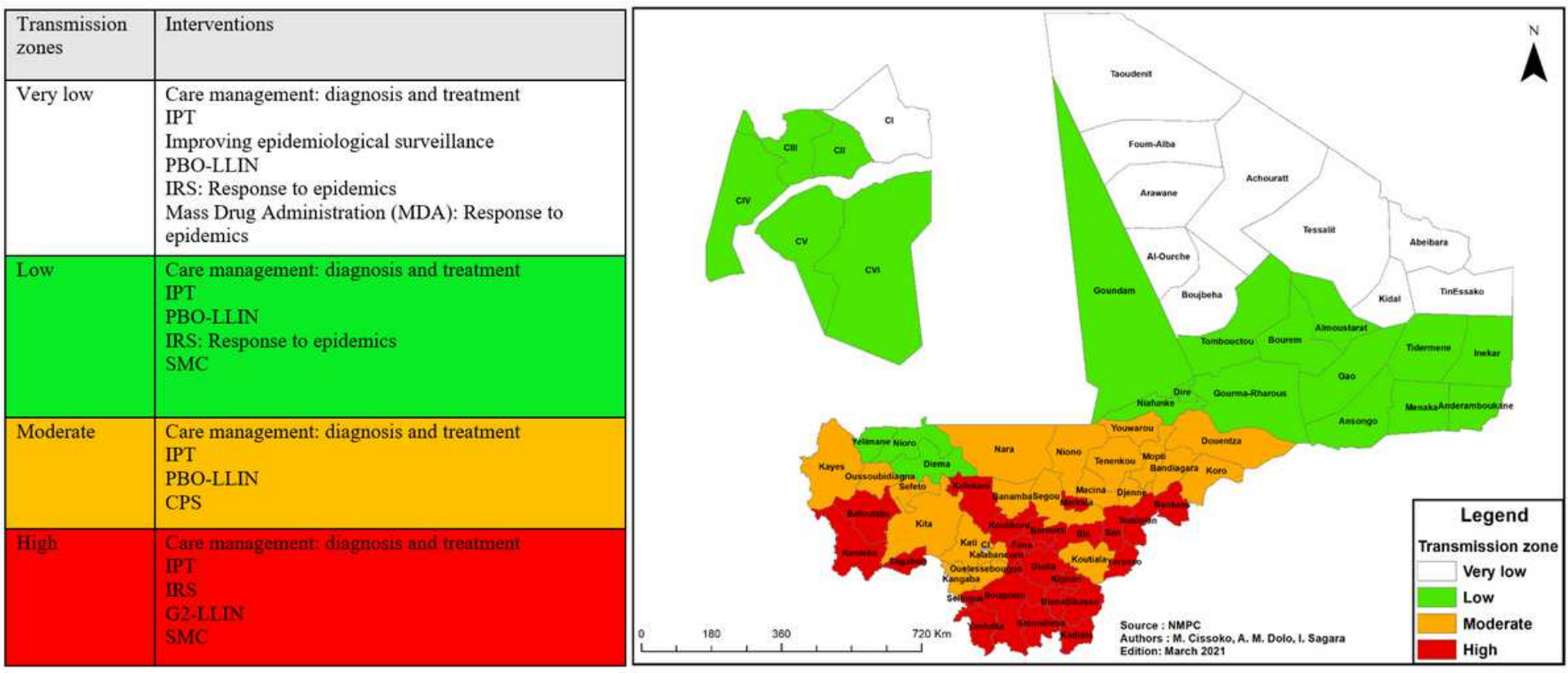

Figure 15

Summary of interventions according to strata. 


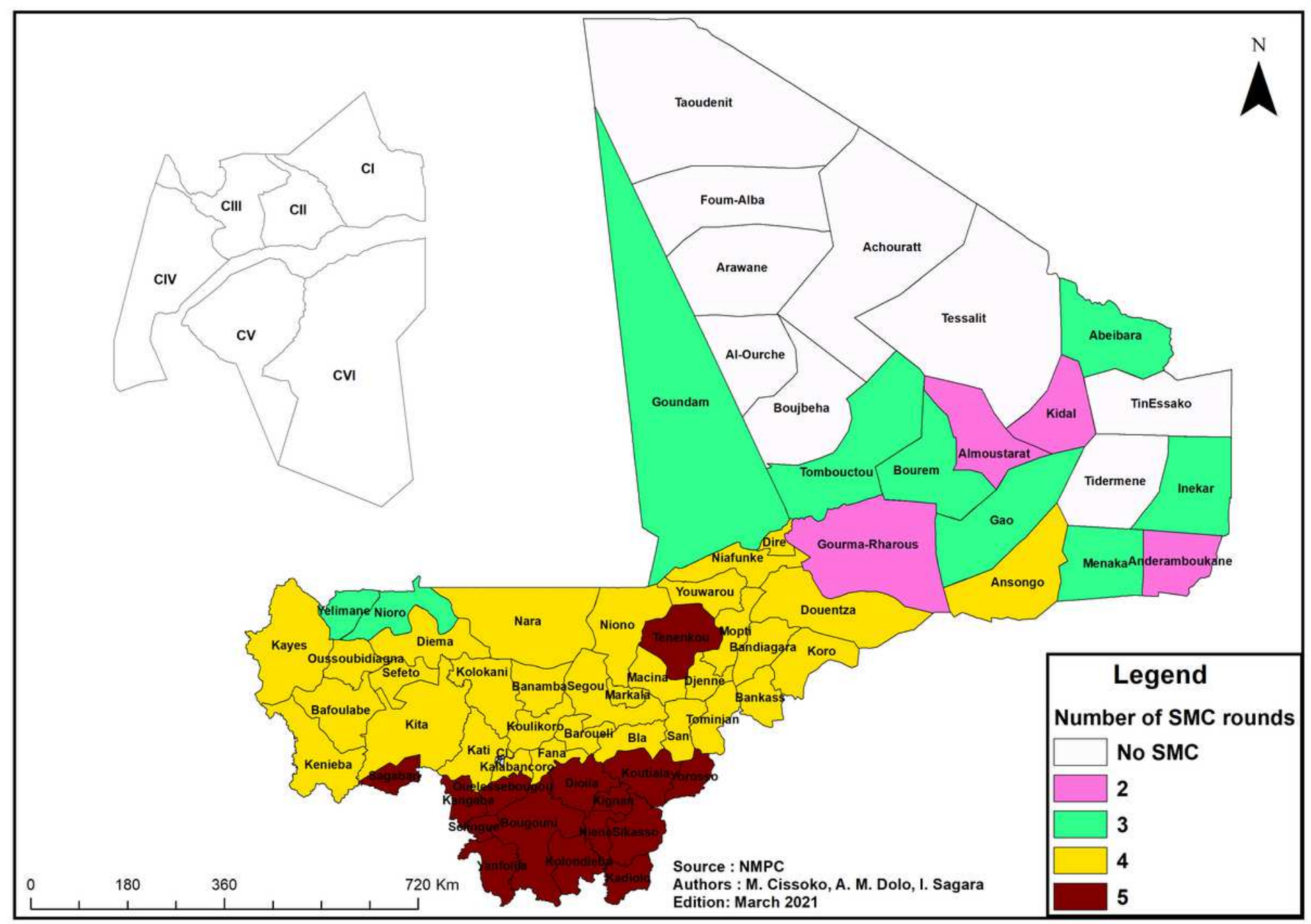

Figure 16

Length of SMC implementation per health district in Mali.

\section{Supplementary Files}

This is a list of supplementary files associated with this preprint. Click to download.

- Supplementary.docx 